the chemistry of this globe and of suns infinitely remote to one common basis. So also is isomorphism an essentially physical phenomenon and one for the explanation of which we shall doubtless be hereafter indebted to physics. The Newton of chemistry may be looked for in the ranks of physicists. In the meantime let us only hope for "new methods" of research-let investigators seek for some method bearing the same relation to our chemistry that the "pneumatic chemistry" of Priestley did to that of his time.

\section{ON TESTIMONIALISM}

UST now, there must be several scientific men asking themselves what can be the conceivable value of testimonials in determining the relative fitness of a number of candidates for any appointment of such importance as a Professorship of a most important branch of natural science in a great seat of learning.

It is not a point of any great difficulty to determine, to one's mental satisfaction, in what cases testimonials are of value - for they are sometimes most useful - and when they are worthless in comparison to other methods for testing the relative efficiency of different men.

Testimonials, or an examination, or the two combined, are no doubt necessary, when the post to be competed for is one, the qualities required for which are not capable of being exhibited to an electoral body by the competitors in any other way. For minor appointments, therefore, such as clerkships, smaller educational posts and the like, they are indispensable; as they are in cases where the intimacy of the relationship between the holder of the post and those he is placed above is close. But for appointments so honourable and responsible as the Professorship of Physiology in the University of Edinburgh, or that of Chemistry in the University of Glasgow, we cannot help thinking that testimonials are a farce. Candidates for such chairs are not youths; they must have had the opportunity of maturing their minds by careful training, during which time frequent opportunities must have occurred for them to take up some fresh branch of their subject and work it out independently, with some originality in the methods they employ. Their confidence in their methods and results ought to have been sufficient to make them publish them, and so expose them to the criticism of the scientific public, who do not generally take long to form a fairly correct estimate of the abilities of authors. If all candidates for important posts were compelled to rely for their election on their works alone as testimonials, we are sure that the electors would be less trammelled, and more in a position to make judicious selections.

By some it may be remarked that what is wanted in the cases above instanced is good teachers, and that if men with original power can be obtained at the same time, so much the better; this requirement makes the general ability of the professor a secondary consideration in comparison with his teaching powers. We are of opinion that this is a mistaken view of the subject. Very frequently the most talented followers of scientific inquiry are not such effective lecturers at first sight as their less-gifted colleagues; still, we never knew a case in which there was not a peculiar charm about the teaching of a master-mind that gives an impulse to study on the part of the student, producing in the long run more beneficial results than the routine discourses of a mere expositor of other people's work. Another thing is that the connection of great names with a seat of learning in itself gives a stimulus to younger workers, raising success in mental work to a position which it is not easy for it to attain, on account of the fact that its results have frequently no immediate practical bearing.

In one at least of the cases we are referring to it is unfortunate in some respects that the electors have no special interest in the science they have so great a power indirectly to advance. In consequence of this their knowledge of the respective merits of the candidates must be uncertain, and we do not think that it will be much increased by the showers of testimonials which it is evidently the intention of more than one of the candidates to submit. One candidate has sent broadcast a lithographed form, sometimes even to men his junior in position and age, courting testimonials. What possibly can be the value of the pound's weight of paper he will probably thus accumulate? He ought to remember that no number of shots from a smooth-bore gun will send a ball as far as a single one from an Armstrong, and on that principle reduce the number and endeavour to increase the quality of the testimonials he sends in; by which means he will save the adjectives as well as the temper of his acquaintances.

Another candidate sends us the printed list of his published works, and to that we see no particular objection. But appended to each is a selected series of reviews, from which all the unfavourable ones are carefully omitted. It is, no doubt, unpleasant to print adverse criticism, but how can the electors be expected to form a correct estimate of the value of the works reviewed, if those in their favour only are introduced? The reviews, as one-sided, had been much better omitted, or, if printed, had much better have been inserted without selection. It is this extreme mode of action thus adopted which has called our attention to the subject.

On the whole, we think that the electors for the Scotch Science Chairs have a by no means easy task before them, and we sincerely hope that in their selection they will lay stress on soundness of judgment and scientific thought rather than on quires of testimonials wrung out of acquaintances and friends, who would much rather have been otherwise employed than in putting pen to paper for the purpose.

Moreover, we are of opinion that not only should a man's researches be taken into account in making an appointment to any science chair, but also that no election should be made without taking the opinion of those competent to form an estimate of the value of these researches.

\section{TRE RAINFALL OF BARBADOS}

Report upon the Rainfall of Barbados, and upon its influence on the Sugar Crops, 1847-1871. With two Supplements, 1873-74. By Governor Rawson, C.B.

THIS Report gives the result of observations made since 1847 , at a large number of stations well distributed over the island. The total area of Barbados s 166 square miles; in 1847 , only three stations had 